food vaccines? Guess what. Not mentioned. The list of omissions is very long. In a pluralist society you do not ban useful products.

Mad? Bad? Dangerous? The only real danger is those who use subjective ideology to corrupt good objective sense.

Anthony Trewavas is at the Institute of Cell and Molecular Biology, University of Edinburgh, Mayfield Road, Edinburgh EH9 3JH, UK.

\section{The age-old problem of mortality}

\author{
The Biology of Death: Origins of \\ Mortality \\ by André Klarsfeld \& Frédéric Revah \\ (transl. Lydia Brady) \\ Cornell University Press: 2003. 204 pp. \\ $\$ 29.95$
}

\section{Caleb E. Finch}

The Biology of Death provides an engaging travelogue for ageing and death, from ancient mythology, the swamps of vitalism and the higher roads of the 'copernican revolution' of experimental gerontology, to today's Société de Thanatologie with its fixation on the ontology of death. The authors, André Klarsfeld and Frédéric Revah, are widely read and show fine taste in their choice of anecdote and historical detail. I was delighted to learn more about the French anatomist Xavier Bichat and the Chevalier de Lamarck. And I hadn't heard before the anecdote about Henry Ford searching junkyards to find parts of his Model $\mathrm{T}$ that never wore out.

The book's style and level of explanation are highly suitable for a general audience. The broad overview of gerontological fact, fiction and theory is basically sound and provides a useful introduction to the perplexities of biological ageing. However, despite the authors' scientific credentials as experimental neurobiologists, some misunderstandings have crept in that will irritate the informed. It is a pity that these were not picked up in review by experts in biogerontology before the publication of either the French edition (Janvier, 2000) or this English translation.

The authors repeat a once common misunderstanding about the Hayflick limit that is still transmitted by the popular press: "These cells stopped dividing and died after having performed a fairly constant number of around fifty divisions." Cellular gerontologists, including Leonard Hayflick, now agree that 'senescent' cultures of fibroblasts can persist in stationary, but metabolically active, states for many months or even years (as do most of our brain and heart cells). Moreover, clonal analysis of daughter cells shows huge differences in the number of subsequent divisions, which are anything

\section{Dress for DNA}

Molecular genetics has proved a rich source of imagery and ideas for contemporary artists, as the DNA sequence/spinal-column dress shown here attests. It forms part of the collection Primitive Streak, a collaboration between designer Helen Storey and her sister Kate, a research biologist. Their work, and that of other artists inspired by the genetic revolution, is the subject of The Molecular Gaze: Art in the Genetic Age (Cold Spring Harbor Laboratory Press, 2004) by artist Suzanne Anker and the late Dorothy Nelkin, a social scientist. Anker and Nelkin seek to place these images in context within the history of art and to provide insight into the social and cultural meaning of the genetic revolution through the gaze of artists. They explore themes including the meaning of mutation and the blurring of species boundaries.

Mary Purton but "fairly constant". The Hayflick limit therefore represents an ensemble average of very heterogeneous cell populations.

This intrinsic heterogeneity confounds interpretations of measurements made on extracts from millions of cells. For example, if gene A goes up and B goes down, relative to a younger stationary culture, it can not be known if A and B have changed in the same cell. The book also implies that the Hayflick limit can be used up during the lifespan. However, the doubling potential of skin fibroblasts does not alter as an adult ages.

The enormous variety of life histories and modes of death in different species of animals and plants intrigues the authors. They draw liberally from examples I collected over 30 years and mentioned in my own book Longevity, Senescence, and the Genome (University of Chicago Press, 1990), which they cite. I had hoped to find some mention of key examples that have since come to light, such as Justin Congdon's description of the negligible senescence of turtles. Dating of individual specimens of fish and other animals with radioisotopes has advanced far beyond the often uncertain counting of old growth rings (G. M. Cailliet et al. Exp. Gerontol. 36, 739-764; 2001). Deep-sea fish in several families in addition to the scorpeanids are now better documented to live beyond 100 years of age, including a gourmands' favourite, the orange roughy. But the anecdote about a 152-year-old sturgeon (Comm. Fish. Rev. 16, 28; 1954 - authors not named), cited without reference, should not have been repeated without a fisherman's wink or a scholar's note - this was a caveat that got away.

The authors' exposition of the evolutionary theory of genetic determinants of longevity is excellent. They provide a lucid review of the classic models of reproductive schedules, which address adaptive trade-offs between number of offspring, initial age of reproduction, reproductive senescence and age-group mortality, and give a basis for the evolutionary selection of lifespan. The authors then give a synthesis of more recent experimental work on fruitflies with field studies on both possums and guppies, which together show that predatory pressure can accelerate reproduction at the apparent expense of longevity. Curiously, though, they do not discuss genetics of longevity in human twins. Several twin studies have shown that lifespan has a relatively low heritability.

For a book on the biology of death it says little about the causes of death at advanced ages, which may be very different to those at younger 'old' ages. For example, for rats whose lifespan was extended by calorie restriction, autopsies revealed so little histopathology in $25 \%$ of rats that causes of death could not be assigned (I. Shimokawa et al. J. Gerontol. 48, B27-32; 1993). It may be that, as the number of very old humans increases, we see cases of death caused by systems failure from multiple small lesions, any one or several of which would not be a sufficient cause on its own. A systems thanatology could be modelled to represent synergies of different levels of dysfunction, with statistical estimates of fluctuations from the norm.

The Biology of Death belongs on the same shelf as other recent popular books on ageing, such as Hayflick's How and Why We Age, Steven Austad's Why We Age and Tom Kirkwood's Time of Our Lives. The remarkable progress being made throughout gerontology has provided scope for the frequent new accounts aimed at the general public.

Caleb Finch is at the Andrus Gerontology Center and Department of Biological Sciences, University of Southern California, Los Angeles, California 90089-0191, USA. 